\title{
Structurally defined nanographene-containing conjugated polymers for high quality dispersions and optoelectronic applications $\uparrow$
}

\author{
Po-I. Wang, ${ }^{a}$ Wojciech Pisula, ${ }^{\mathrm{b}}$ Klaus Müllen ${ }^{\mathrm{b}}$ and Der-Jang Liaw ${ }^{\star a}$
}

Novel conjugated polymers such as poly(phenylene-fluorene) P1 and poly(triphenylbenzene-fluorene) P2 with hexaphenylbenzene (HPB) as a pending side group were prepared by Suzuki coupling using the dibromo monomers M1 and M2 with 9,9-dioctylfluorene-2,7-diboronic acid bis(1,3-propanediol) ester, respectively. The HPB moiety of $\mathbf{P} 1$ and $\mathbf{P} 2$ can be oxidatively cyclodehydrogenated with $\mathrm{FeCl}_{3}$ in nitromethane, yielding polymers P3 and P4 with hexa-peri-hexabenzocoronene (i.e., nanographene) units. The cyclodehydrogenation of nanographene-containing polymers was confirmed by FT-IR spectroscopy. In addition, X-ray powder diffraction of both P3 and P4 revealed a polymer interlayer spacing of $1.3 \mathrm{~nm}$ being dominated by the nanographenes. The glass transition temperatures $\left(T_{\mathrm{g}} \mathrm{s}\right)$ of $\mathbf{P} \mathbf{1}$ and $\mathbf{P} 2$ were $202^{\circ} \mathrm{C}$ and $235^{\circ} \mathrm{C}$, respectively, while both $\mathbf{P} 3$ and $\mathbf{P 4}$ with nanographenes possessed $T_{\mathrm{g}}$ s higher than $300{ }^{\circ} \mathrm{C}$. Compared to P3, P4 with a triphenylbenzene moiety in its backbone can be well dispersed without aggregation in N-cyclohexyl-2-pyrrolidone (CHP), as confirmed by UV-Vis spectroscopy, photoluminescence spectroscopy $(\mathrm{PL})$ and photoluminescence-excitation (PLE) maps.

Received 30th July 2016,

Accepted 13th September 2016

DOI: $10.1039 /$ c6py01330a

www.rsc.org/polymers sists of benzenoid rings in linear or angular arrangements such as anthracene, tetracene, phenanthrene or tetraphene. peri-Condensed polyarenes are another major class of PAHs, examples of which are pyrene, ovalene and hexa-peri-hexabenzocoronenes (HBCs).

Hexa-peri-hexabenzocoronenes (HBCs) are an example of PAHs and have the chemical formula $\mathrm{C}_{42} \mathrm{H}_{18}$. The first synthesis of HBCs was performed using dibenzo-peri-naphthene by Erich Clar and coworkers in 1958. Halleux et al. and Schmidt et al. have reported different routes for synthesizing HBCs through the cyclization of precursors. However, all methods of synthesizing HBCs give low yields and require complicated workups. ${ }^{5}$ Therefore, Müllen and coworkers developed an efficient way to prepare HBCs through Scholl-type intramolecular oxidative cyclodehydrogenation by treating hexaphenylbenzene (HPB) with $\mathrm{Cu}(\mathrm{OTf})_{2} / \mathrm{AlCl}_{3}$ in $\mathrm{CS}_{2}$, or $\mathrm{FeCl}_{3}$ dissolved in nitromethane. ${ }^{6}$ This method has been used for the preparation of complex PAHs with different sizes and shapes. ${ }^{7}$ In recent years, HBCs and their derivatives have attracted attention due to their high symmetry, high stability, high charge carrier mobility and self-assembly. HBCs and their derivatives have been widely used in synthetic chemistry, liquid crystalline mesophases and optoelectronics. ${ }^{8-10}$ HBCs have been considered "nano-graphene" or "super-benzene" due to their large $\pi$-system with 13 benzenes and $D_{6 \mathrm{~h}}$-symmetry. HBCs can also be considered a prototype for giant and planar PAHs including $\mathrm{C}_{222} \mathrm{H}_{42}, \mathrm{C}_{474} \mathrm{H}_{66}$, and graphene nano- 
ribbons. However, these planar hydrocarbons are generally insoluble in common solvents as a result of their strong $\pi-\pi$ stacking interactions. To enhance the solubility of HBCs, peripheral alkyl groups should be incorporated. ${ }^{11}$ These HBC derivatives with substituents can be cast into films through a solution process and used for applications such as organic light-emitting diodes, organic photovoltaics and thin film transistors. ${ }^{12}$

For reasons of atom economy and to broaden the scope of the synthesis of various HBC materials, non-substituted HBCs carry the great advantage of their simple synthesis. The thermal properties and carrier mobility of HBCs will not be affected by aliphatic alkyl chains. The unsubstituted HBC dispersion via ultrasonic agitation was found to be an efficient method both in organic solvents and in aqueous surfactant solution, but aggregation phenomena of HBCs were observed when HBCs were dispersed in poor solvents or unsuitable surfactant systems. ${ }^{13,14}$ As reported by Coleman et al., amide solvents such as cyclohexylpyrrolidone (CHP) perform well when dispersing single-walled carbon nanotubes (SWCNTs) and graphenes. ${ }^{15}$ The dispersion of HBC derivatives was limited to the selection of an amide solvent or a specific surfactant in an aqueous solvent. Therefore, we demonstrate the dispersion of a conjugated polymer bearing a HBC moiety to improve the dispersibility in various organic solvents.
In this study, the conjugated polymers P1 and P2 were synthesized from a dibromo monomer with a non-substituted HPB unit and a diboronic ester monomer of dioctyl-fluorene (Scheme 1). The solubility of the polymer is enhanced by the addition of flexible fluorene alkyl-chains, and premature precipitation during polymerization is avoided. In addition, HPB can be regarded as a precursor of HBCs, and the conjugated polymers P3 and P4 with a HBC moiety can be prepared by a Scholl reaction. To confirm cyclodehydrogenation, P1-P4 were studied using FT-IR spectroscopy and X-ray powder diffraction to identify HPB and HBC units. To the best of our knowledge, exfoliation of the HBC-containing conjugated polymer has not been reported yet. We prepared dispersions of P3 and P4 for spectroscopic characterization using UV-Vis spectroscopy, PL spectroscopy and photoluminescence-excitation (PLE) maps.

\section{Experimental}

\section{Materials}

(4-Bromophenyl)pentaphenylbenzene (1) was prepared via Diels-Alder cycloaddition according to a procedure reported by Müllen et $a .^{16}$ 1,3,5-Tri(4-bromophenyl)benzene was synthesized by the cyclocondensation of $p$-bromoacetophenone. ${ }^{17}$ 4-Bromoiodobenzene, copper iodide (CuI), diphenyl ether,
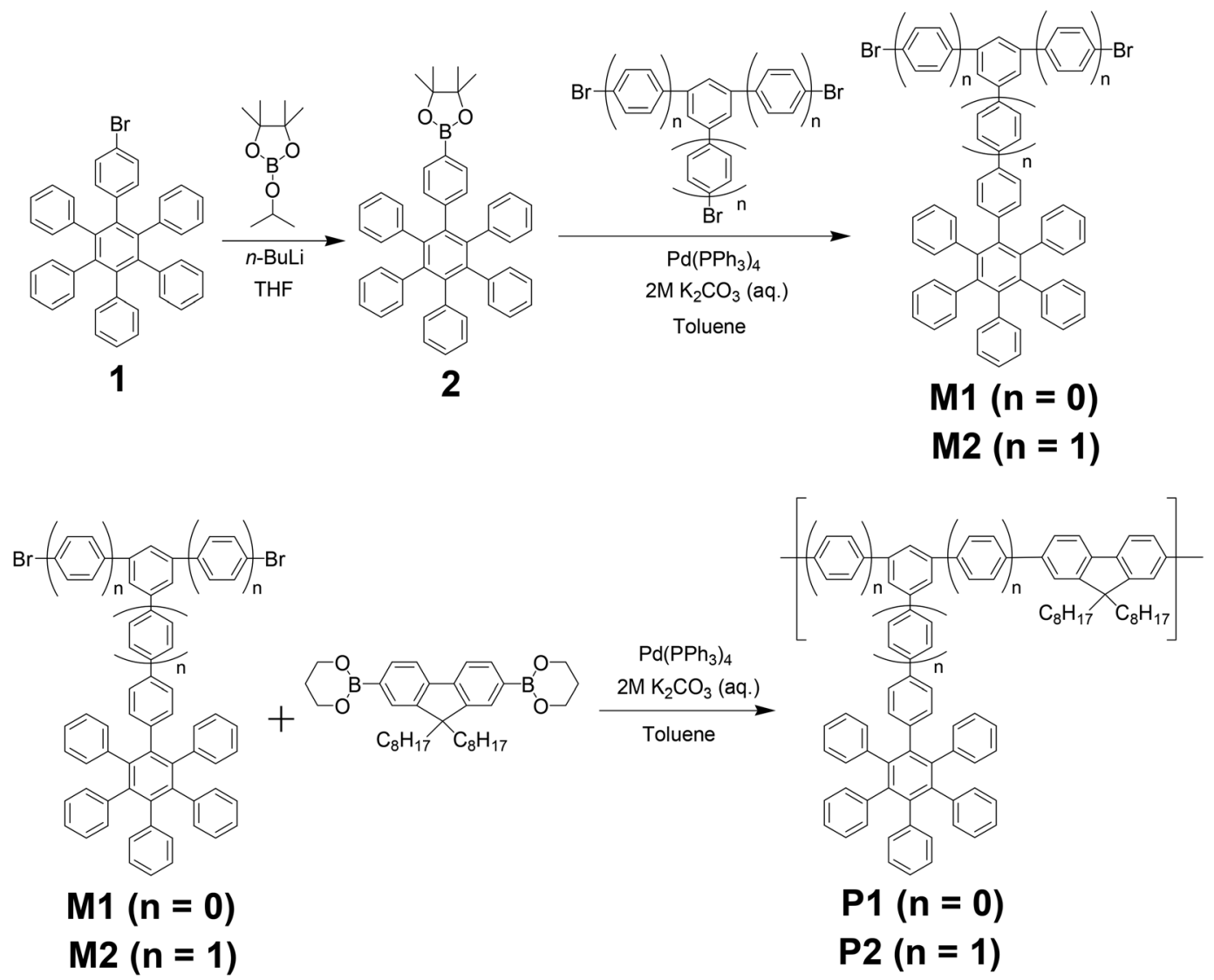

Scheme 1 The synthesis of HPB-containing monomers M1 and M2 as well as conjugated polymers P1 and P2. 
iron(III) chloride $\left(\mathrm{FeCl}_{3}\right)$, phenylacetylene, piperidine, 7,7,8,8tetracyanoquinodimethane (TCNQ) and tetrakis(triphenylphosphine)palladium $(0) \quad\left(\mathrm{Pd}\left(\mathrm{PPh}_{3}\right)_{4}\right)$ were purchased from Acros Organics. Anhydrous potassium carbonate $\left(\mathrm{K}_{2} \mathrm{CO}_{3}\right)$ was purchased from Fisher Chemical. 9,9-Dioctylfluorene-2,7diboronic acid bis(1,3-propanediol) ester, $n$-butyllithium solution (2.5 $\mathrm{M}$ in hexanes), 2-isopropoxy-4,4,5,5-tetramethyl[1,3,2] dioxaborolane, $p$-bromoacetophenone and tetraphenylcyclopentadienone were purchased from Sigma-Aldrich Chemical Co. The solvents (analytical grade) were purchased from Merck. Tetrahydrofuran and toluene were distilled from sodium/benzophenone (deep purple) under nitrogen before use. All other reagents were used as received.

\section{Measurements}

IR spectra were recorded in the range $400-4200 \mathrm{~cm}^{-1}$ for synthesized monomers and polymers in a $\mathrm{KBr}$ disk (Bio-Rad Digilab FTS-3500). NMR spectra were recorded using a Bruker Avance III HD-600 $\left({ }^{1} \mathrm{H}\right.$ at $600 \mathrm{MHz}$ and ${ }^{13} \mathrm{C}$ at $\left.150 \mathrm{MHz}\right)$. Differential scanning calorimetric analysis was performed on a differential scanning calorimeter (TA Instrument TA 910) under nitrogen at a flow rate of $50 \mathrm{~cm}^{3} \mathrm{~min}^{-1}$ and a heating rate of $10 \mathrm{~K} \mathrm{~min}^{-1}$. Thermogravimetric analysis was performed on a TA Instrument Dynamic TGA 2950 under nitrogen at a flow rate of $30 \mathrm{~cm}^{3} \mathrm{~min}^{-1}$ and a heating rate of $10 \mathrm{~K} \mathrm{~min}^{-1}$. $\mathrm{X}$-ray diffraction experiments were performed using a Bruker

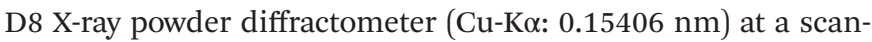
ning rate of $0.1^{\circ}$ per $20 \mathrm{~s}$. Mass spectra were obtained using a Bruker micro TOF-QII and MALDI-TOF MS spectra were characterized by using a BrukerAutoflex III TOF/TOF (using TCNQ as a matrix). Weight-average $\left(M_{\mathrm{w}}\right)$ and number-average $\left(M_{\mathrm{n}}\right)$ molecular weights were determined by gel permeation chromatography (GPC). Four Waters (Ultrastyragel) columns $(300 \times 7.5 \mathrm{~mm}$, guard, 105, 104, 103, and $500 \AA$ in a series) were used for GPC analysis with tetrahydrofuran (THF; $1 \mathrm{~mL} \mathrm{~min}^{-1}$ ) as the eluent. The eluents were monitored with a UV detector (JMST Systems, VUV-24, USA) at $254 \mathrm{~nm}$, and polystyrene was used as the standard. The UV-Vis absorption spectra of the specimens were recorded on a JASCO V-670 spectrophotometer at room temperature in air. Photoluminescence (PL) spectra and photoluminescenceexcitation (PLE) maps were obtained using a HORIBA JOBIN FluoroMax-3 with a $1 \mathrm{~cm} \times 1 \mathrm{~cm}$ quartz cuvette. The photoluminescence quantum yield $\left(\Phi_{\mathrm{PL}}\right)$ values of the samples in dilute THF solution were measured in an integrating sphere using 9,10-diphenylanthracence in cyclohexane as a reference $\left(\Phi_{\mathrm{PL}}=0.9\right)$. A cyclic voltammeter $(\mathrm{CV}$; CHI model $619 \mathrm{~A})$ was used to measure oxidative potentials with a standard threeelectrode electrochemical cell in an acetonitrile solution containing $0.1 \mathrm{M}$ tetrabutylammoniumperchlorate (TBAP) at room temperature under argon (scanning rate $=0.1 \mathrm{~V} \mathrm{~s}^{-1}$ ).

\section{Synthesis of 4-(4,4,5,5-tetramethyl-1,3,2-dioxaborolan-2-yl- phenyl)pentaphenylbenzene (2)}

To a solution of (4-bromophenyl)pentaphenylbenzene (1) $(1 \mathrm{~g}$, $1.63 \mathrm{mmol})$ in anhydrous THF $(150 \mathrm{~mL})$ under nitrogen at
$-78{ }^{\circ} \mathrm{C}, n$-butyllithium $(2.5 \mathrm{M}$ in hexane, $1.3 \mathrm{~mL}, 3.26 \mathrm{mmol})$ was added and stirred at $-78{ }^{\circ} \mathrm{C}$ for $30 \mathrm{~min}$. 2-Isopropoxy4,4,5,5-tetramethyl-[1,3,2]dioxaborolane (0.91 g, $4.89 \mathrm{mmol})$ was added at $-78{ }^{\circ} \mathrm{C}$, and the resulting solution was stirred at room temperature for $6 \mathrm{~h}$. Water $(5 \mathrm{~mL})$ was added to quench the reaction, followed by solvent removal using a rotary evaporator. The crude products were dissolved in dichloromethane $(50 \mathrm{~mL})$, extracted with brine $(30 \mathrm{~mL} \times 3)$, dried with $\mathrm{MgSO}_{4}$ and concentrated in a vacuum. The residue was purified by column chromatography (silica gel, $n$-hexane $/ \mathrm{CH}_{2} \mathrm{Cl}_{2}=3 / 1$ ) to obtain white powders $(0.75 \mathrm{~g}$, yield $=70 \%)$. IR $(\mathrm{KBr})$ : $4050 \mathrm{~cm}^{-1}, 3078 \mathrm{~cm}^{-1}, 3051 \mathrm{~cm}^{-1}$ and $3022 \mathrm{~cm}^{-1}$ (Ar-H stretch), $2978 \mathrm{~cm}^{-1}, 2929 \mathrm{~cm}^{-1}$, and $2864 \mathrm{~cm}^{-1}$ (C-H stretch), $1614 \mathrm{~cm}^{-1}, 1598 \mathrm{~cm}^{-1}$ and $1494 \mathrm{~cm}^{-1}$ ( $\mathrm{C}=\mathrm{C}$ stretch in $\mathrm{Ar}$ ), $696 \mathrm{~cm}^{-1} .{ }^{1} \mathrm{H}$ NMR $\left(600 \mathrm{MHz}, \mathrm{CD}_{2} \mathrm{Cl}_{2}, \mathrm{Me}_{4} \mathrm{Si}\right): \delta(\mathrm{ppm})=1.25$ $\left(\mathrm{s}, 12 \mathrm{H}, \mathrm{H}_{\mathrm{c}}\right), 6.84-6.89(\mathrm{~m}, 25 \mathrm{H}$, phenyl- $\mathrm{H}), 6.90(\mathrm{~d}, 2 \mathrm{H}, J=8.4$ $\left.\mathrm{Hz}, \mathrm{H}_{\mathrm{a}}\right), 7.22\left(\mathrm{~d}, 2 \mathrm{H}, J=7.8 \mathrm{~Hz}, \mathrm{H}_{\mathrm{b}}\right) ;{ }^{13} \mathrm{C}$ NMR $(150 \mathrm{MHz}$, $\left.\mathrm{CD}_{2} \mathrm{Cl}_{2}, \mathrm{Me}_{4} \mathrm{Si}\right): \delta(\mathrm{ppm})=25.29\left(\mathrm{C}_{3}\right), 84.20\left(\mathrm{C}_{6}\right), 125.75$, 125.84, 127.06, 127.13, $131.36\left(\mathrm{C}_{1}\right), 131.92,133.42\left(\mathrm{C}_{2}\right), 140.63$ $\left(\mathrm{C}_{5}\right), 140.71,140.96,141.19,141.28,141.31,144.38\left(\mathrm{C}_{4}\right)$.

\section{Synthesis of 4'-(1,3-dibromophenyl)hexaphenylbenzene (M1)}

Compound (2) (0.6 g, $0.91 \mathrm{mmol})$, tribromobenzene $(0.31 \mathrm{~g}$, $1 \mathrm{mmol})$, and $\mathrm{Pd}\left(\mathrm{PPh}_{3}\right)_{4}(23 \mathrm{mg}, 0.02 \mathrm{mmol})$ were dissolved in degassed toluene $(10 \mathrm{~mL})$ and added to a three-neck roundbottom flask with a condenser. Then, $2 \mathrm{M}$ aqueous solution of $\mathrm{K}_{2} \mathrm{CO}_{3}(8 \mathrm{~mL})$ was added. The mixture was vigorously stirred at $105{ }^{\circ} \mathrm{C}$ for $12 \mathrm{~h}$ under flowing nitrogen. After cooling, the resulting mixture was extracted with toluene/water twice, after which the organic layer was separated and concentrated using a rotary evaporator. The residue was purified by column chromatography (silica gel, $n$-hexane $/ \mathrm{CH}_{2} \mathrm{Cl}_{2}=4 / 1$ ) to produce white powders $(0.42 \mathrm{~g}$, yield $=60 \%)$. IR $(\mathrm{KBr}): 4054 \mathrm{~cm}^{-1}$, $3078 \mathrm{~cm}^{-1}, 3059 \mathrm{~cm}^{-1}$ and $3024 \mathrm{~cm}^{-1}$ (Ar-H stretch), $1600 \mathrm{~cm}^{-1}, 1581 \mathrm{~cm}^{-1}$ and $1539 \mathrm{~cm}^{-1}(\mathrm{C}=\mathrm{C}$ stretch in $\mathrm{Ar})$, $698 \mathrm{~cm}^{-1}$. ${ }^{1} \mathrm{H}$ NMR $\left(600 \mathrm{MHz}, \mathrm{CDCl}_{3}, \mathrm{Me}_{4} \mathrm{Si}\right): \delta(\mathrm{ppm})=$ 6.82-6.90 (m, 25H, phenyl-H), $6.92\left(\mathrm{~d}, 2 \mathrm{H}, J=8.4 \mathrm{~Hz}, \mathrm{H}_{\mathrm{a}}\right), 7.05$ $\left(\mathrm{d}, 2 \mathrm{H}, J=8.4 \mathrm{~Hz}, \mathrm{H}_{\mathrm{b}}\right), 7.50\left(\mathrm{~s}, 2 \mathrm{H}, \mathrm{H}_{\mathrm{c}}\right), 7.53\left(\mathrm{~s}, 1 \mathrm{H}, \mathrm{H}_{\mathrm{d}}\right)$. ${ }^{13} \mathrm{C}$ NMR $\left(150 \mathrm{MHz}, \mathrm{CD}_{2} \mathrm{Cl}_{2}, \mathrm{Me}_{4} \mathrm{Si}\right): \delta(\mathrm{ppm})=123.03\left(\mathrm{C}_{8}\right)$, $125.10\left(\mathrm{C}_{2}\right), 125.24,125.36,126.60,126.72,128.53\left(\mathrm{C}_{3}\right), 131.38$, $132.07\left(\mathrm{C}_{4}\right), 132.10\left(\mathrm{C}_{1}\right), 134.56\left(\mathrm{C}_{6}\right), 139.44,140.27,140.42$, $140.47,140.50,140.62,141.27\left(\mathrm{C}_{5}\right), 144.38\left(\mathrm{C}_{7}\right)$.

\section{Synthesis of 4'-[5,7-bis(4-bromophenyl)biphenyl] hexaphenylbenzene (M2)}

The title compound (M2) was prepared in a manner analogous to the procedure of $\mathbf{M} 1$ to obtain the product as white powders (yield = 65\%). IR (KBr): $4054 \mathrm{~cm}^{-1}, 3080 \mathrm{~cm}^{-1}, 3055 \mathrm{~cm}^{-1}$ and $3024 \mathrm{~cm}^{-1}$ (Ar-H stretch), $1598 \mathrm{~cm}^{-1}$ and $1489 \mathrm{~cm}^{-1}(\mathrm{C}=\mathrm{C}$ stretch in $\mathrm{Ar}), 1072 \mathrm{~cm}^{-1}(\mathrm{Ar}-\mathrm{Br}), 698 \mathrm{~cm}^{-1} \cdot{ }^{1} \mathrm{H}$ NMR $\left(600 \mathrm{MHz}, \mathrm{CDCl}_{3}, \mathrm{Me}_{4} \mathrm{Si}\right): \delta(\mathrm{ppm})=6.85-6.92(\mathrm{~m}, 25 \mathrm{H}$, phenyl-H), $6.94\left(\mathrm{~d}, 2 \mathrm{H}, J=8.4 \mathrm{~Hz}, \mathrm{H}_{\mathrm{a}}\right), 7.21(\mathrm{~d}, 2 \mathrm{H}, J=8.4 \mathrm{~Hz}$, $\left.\mathrm{H}_{\mathrm{b}}\right), 7.54\left(\mathrm{~d}, 4 \mathrm{H}, J=8.4 \mathrm{~Hz}, \mathrm{H}_{\mathrm{g}}\right), 7.56\left(\mathrm{~d}, 2 \mathrm{H}, J=8.4 \mathrm{~Hz}, \mathrm{H}_{\mathrm{c}}\right.$ ), $7.61\left(\mathrm{~d}, 4 \mathrm{H}, J=8.4 \mathrm{~Hz}, \mathrm{H}_{\mathrm{h}}\right), 7.64\left(\mathrm{~d}, 2 \mathrm{H}, J=7.8 \mathrm{~Hz}, \mathrm{H}_{\mathrm{d}}\right), 7.67$ (s, $\left.1 \mathrm{H}, \mathrm{H}_{\mathrm{f}}\right), 7.73\left(\mathrm{~s}, 2 \mathrm{H}, \mathrm{H}_{\mathrm{e}}\right) ;{ }^{13} \mathrm{C} \mathrm{NMR}\left(150 \mathrm{MHz}, \mathrm{CD}_{2} \mathrm{Cl}_{2}, \mathrm{Me}_{4} \mathrm{Si}\right)$ : $\delta(\mathrm{ppm})=121.97\left(\mathrm{C}_{16}\right), 124.59\left(\mathrm{C}_{6}\right), 125.01\left(\mathrm{C}_{2}+\mathrm{C}_{5}\right), 125.21$, 
125.25, 126.59, 126.68, $127.14\left(\mathrm{C}_{3}\right), 127.42\left(\mathrm{C}_{4}\right), 128.90\left(\mathrm{C}_{7}\right)$, 131.42, 131.45, $131.96\left(\mathrm{C}_{1}\right), 131.99\left(\mathrm{C}_{8}\right), 136.60\left(\mathrm{C}_{10}\right), 139.12$ $\left(\mathrm{C}_{12}\right), 139.82\left(\mathrm{C}_{15}\right), 140.13\left(\mathrm{C}_{11}\right), 140.20\left(\mathrm{C}_{9}\right), 140.35,140.43$, 140.48, 140.58, $141.34\left(\mathrm{C}_{14}\right), 142.23\left(\mathrm{C}_{13}\right)$.

Synthesis of poly[4'-(1,3-phenyl)]hexaphenylbenzene-alt-2,7(9,9-dioctylfluorene) (P1) via Suzuki coupling

The dibromo monomer (M1) (0.2093 g, $0.273 \mathrm{mmol}$ ), 9,9-dioctylfluorene-2,7-diboronic acid bis(1,3-propanediol) ester (0.1522 g, $0.273 \mathrm{mmol})$, and $\mathrm{Pd}\left(\mathrm{PPh}_{3}\right)_{4}(6.3 \mathrm{mg}, 0.05 \mathrm{mmol})$ were dissolved in degassed toluene $(10 \mathrm{~mL})$ and added to a three-neck round-bottom flask with a condenser and a $2 \mathrm{M}$ aqueous solution of $\mathrm{K}_{2} \mathrm{CO}_{3}(8 \mathrm{~mL})$. The resulting solution was stirred at $105{ }^{\circ} \mathrm{C}$ for $48 \mathrm{~h}$ under the flow of nitrogen. After cooling, the solution was extracted with toluene/water twice to remove the base. The organic layer was separated, concentrated by using a rotary evaporator and precipitated in excess methanol. The grey fibrous product was filtered and purified by Soxhlet extraction with acetone for $48 \mathrm{~h}(0.25 \mathrm{~g}$, yield = 92\%). IR (KBr): $4046 \mathrm{~cm}^{-1}, 3078 \mathrm{~cm}^{-1}, 3055 \mathrm{~cm}^{-1}$ and $3028 \mathrm{~cm}^{-1}$ (Ar-H stretch), $2955 \mathrm{~cm}^{-1}, 2924 \mathrm{~cm}^{-1}$ and $2854 \mathrm{~cm}^{-1}$ (C-H stretch), $1597 \mathrm{~cm}^{-1}$ and $1496 \mathrm{~cm}^{-1}(\mathrm{C}=\mathrm{C}$ stretch in Ar), $748 \mathrm{~cm}^{-1}, 698 \mathrm{~cm}^{-1} .{ }^{1} \mathrm{H} \mathrm{NMR}\left(600 \mathrm{MHz}, \mathrm{CDCl}_{3}\right.$, $\left.\mathrm{Me}_{4} \mathrm{Si}\right): \delta(\mathrm{ppm})=0.70-0.92\left(\mathrm{~m}, 10 \mathrm{H}, \mathrm{H}_{\mathrm{i}}, \mathrm{H}_{\mathrm{o}}\right), 1.02-1.22(\mathrm{~m}$, $\left.16 \mathrm{H}, \mathrm{H}_{\mathrm{j}}, \mathrm{H}_{\mathrm{k}}, \mathrm{H}_{\mathrm{l}}, \mathrm{H}_{\mathrm{m}}\right), 1.19\left(\mathrm{~m}, 4 \mathrm{H}, \mathrm{H}_{\mathrm{n}}\right), 2.09\left(\mathrm{~s}, 4 \mathrm{H}, \mathrm{H}_{\mathrm{h}}\right.$ ), 6.75-6.92 (m, 25H, phenyl-H), $6.98\left(\mathrm{~d}, 2 \mathrm{H}, \mathrm{H}_{\mathrm{a}}\right), 7.35(\mathrm{~d}, 2 \mathrm{H}$, $\left.\mathrm{H}_{\mathrm{b}}\right), 7.54\left(2 \mathrm{H}, \mathrm{H}_{\mathrm{c}}\right), 7.63\left(2 \mathrm{H}, \mathrm{H}_{\mathrm{g}}\right), 7.68\left(2 \mathrm{H}, \mathrm{H}_{\mathrm{e}}\right), 7.74\left(1 \mathrm{H}, \mathrm{H}_{\mathrm{d}}\right)$, $7.81\left(2 \mathrm{H}, \mathrm{H}_{\mathrm{f}}\right) ;{ }^{13} \mathrm{C} \mathrm{NMR}\left(150 \mathrm{MHz}, \mathrm{CDCl}_{3}, \mathrm{Me}_{4} \mathrm{Si}\right): \delta(\mathrm{ppm})=$ $14.04\left(\mathrm{C}_{15}\right), 22.57\left(\mathrm{C}_{14}\right), 23.87\left(\mathrm{C}_{9}\right), 29.18\left(\mathrm{C}_{11}+\mathrm{C}_{12}\right), 30.02$ $\left(\mathrm{C}_{10}\right), 31.72\left(\mathrm{C}_{13}\right), 40.43\left(\mathrm{C}_{8}\right), 55.45\left(\mathrm{C}_{23}\right), 119.39,120.04\left(\mathrm{C}_{6}\right)$, $121.60\left(\mathrm{C}_{7}\right), 124.53\left(\mathrm{C}_{4}\right), 124.82\left(\mathrm{C}_{3}\right), 125.04\left(\mathrm{C}_{2}\right), 125.21,126.15$ $\left(\mathrm{C}_{5}\right), 126.59,126.69,127.85,131.11,131.43,132.02\left(\mathrm{C}_{1}\right), 137.25$ $\left(\mathrm{C}_{17}\right), 140.16,140.37,140.48,140.60\left(\mathrm{C}_{16}+\mathrm{C}_{18}+\mathrm{C}_{19}+\mathrm{C}_{20}\right)$, $151.90\left(\mathrm{C}_{22}\right) \cdot M_{\mathrm{n}}=21400 \mathrm{~g} \mathrm{~mol}^{-1}$ and PDI = 1.34 by GPC.

\section{Synthesis of poly[4'-(5,7-(4,4-diphenyl)biphenyl)] hexaphenylbenzene-alt-2,7-(9,9-dioctylfluorene) (P2) via Suzuki coupling}

The title compound (P2) was prepared in a manner analogous to the procedure of $\mathbf{P 1}$ to obtain a grey fibrous product (yield = 90\%). IR (KBr): $4042 \mathrm{~cm}^{-1}, 3080 \mathrm{~cm}^{-1}, 3055 \mathrm{~cm}^{-1}$ and $3026 \mathrm{~cm}^{-1}$ (Ar-H stretch), $2949 \mathrm{~cm}^{-1}, 2920 \mathrm{~cm}^{-1}$ and $2848 \mathrm{~cm}^{-1}$ (C-H stretch), $1585 \mathrm{~cm}^{-1}$ and $1502 \mathrm{~cm}^{-1}(\mathrm{C}=\mathrm{C}$ stretch in Ar), $748 \mathrm{~cm}^{-1}, 696 \mathrm{~cm}^{-1} .{ }^{1} \mathrm{H}$ NMR (600 MHz, $\mathrm{CDCl}_{3}$, $\left.\mathrm{Me}_{4} \mathrm{Si}\right): \delta(\mathrm{ppm})=0.78-0.85\left(\mathrm{~m}, 10 \mathrm{H}, \mathrm{H}_{\mathrm{m}}, \mathrm{H}_{\mathrm{s}}\right), 1.07-1.18(\mathrm{~m}$, $\left.16 \mathrm{H}, \mathrm{H}_{\mathrm{n}}, \mathrm{H}_{\mathrm{o}}, \mathrm{H}_{\mathrm{p}}, \mathrm{H}_{\mathrm{q}}\right), 1.21\left(\mathrm{~m}, 4 \mathrm{H}, \mathrm{H}_{\mathrm{r}}\right), 2.11\left(\mathrm{~s}, 4 \mathrm{H}, \mathrm{H}_{\mathrm{l}}\right)$, 6.82-6.93 (m, 25H, phenyl-H), $6.95\left(\mathrm{~d}, 2 \mathrm{H}, J=7.8 \mathrm{~Hz}, \mathrm{H}_{\mathrm{a}}\right), 7.25$ $\left(\mathrm{d}, 2 \mathrm{H}, J=8.4 \mathrm{~Hz}, \mathrm{H}_{\mathrm{b}}\right), 7.63\left(\mathrm{~d}, 2 \mathrm{H}, J=8.4 \mathrm{~Hz}, \mathrm{H}_{\mathrm{c}}\right), 7.67(\mathrm{~s}, 2 \mathrm{H}$, $\mathrm{H}_{\mathrm{k}}$ ), $7.71\left(\mathrm{~d}, 2 \mathrm{H}, J=8.4 \mathrm{~Hz}, \mathrm{H}_{\mathrm{i}}\right), 7.75\left(\mathrm{~d}, 2 \mathrm{H}, J=7.8 \mathrm{~Hz}, \mathrm{H}_{\mathrm{d}}\right.$ ), 7.81-7.88 (m, 10H, $\left.\mathrm{H}_{\mathrm{g}}, \mathrm{H}_{\mathrm{h}}, \mathrm{H}_{\mathrm{j}}\right), 7.89\left(\mathrm{~s}, 2 \mathrm{H}, \mathrm{H}_{\mathrm{e}}\right), 7.93(\mathrm{~s}, 1 \mathrm{H}$, $\left.\mathrm{H}_{\mathrm{f}}\right) ;{ }^{13} \mathrm{C}$ NMR $\left(150 \mathrm{MHz}, \mathrm{CDCl}_{3}, \mathrm{Me}_{4} \mathrm{Si}\right): \delta(\mathrm{ppm})=14.06\left(\mathrm{C}_{19}\right)$, $22.59\left(\mathrm{C}_{18}\right), 23.87\left(\mathrm{C}_{13}\right), 29.20\left(\mathrm{C}_{15}+\mathrm{C}_{16}\right), 30.04\left(\mathrm{C}_{14}\right), 31.78$ $\left(\mathrm{C}_{17}\right), 40.48\left(\mathrm{C}_{12}\right), 55.36\left(\mathrm{C}_{31}\right), 120.14\left(\mathrm{C}_{10}\right), 121.49\left(\mathrm{C}_{11}\right), 125.04$ $\left(\mathrm{C}_{6}\right), 125.21\left(\mathrm{C}_{5}\right), 125.26\left(\mathrm{C}_{2}\right), 126.02\left(\mathrm{C}_{9}\right), 126.59$, 126.69, $127.17\left(\mathrm{C}_{3}\right), 127.20,127.39,127.53\left(\mathrm{C}_{4}\right), 127.67\left(\mathrm{C}_{8}\right), 127.77$ $\left(\mathrm{C}_{7}\right), 128.77,131.44,131.47,131.97\left(\mathrm{C}_{1}\right), 136.72\left(\mathrm{C}_{21}\right), 139.53$
$\left(\mathrm{C}_{28}\right), 139.64\left(\mathrm{C}_{23}\right), 139.91\left(\mathrm{C}_{20}+\mathrm{C}_{22}+\mathrm{C}_{26}\right), 140.08\left(\mathrm{C}_{27}\right), 140.25$ $\left(\mathrm{C}_{29}\right), 140.38,140.43,140.60,140.99\left(\mathrm{C}_{24}\right), 142.09\left(\mathrm{C}_{25}\right), 151.83$ $\left(\mathrm{C}_{30}\right) \cdot M_{\mathrm{n}}=24900 \mathrm{~g} \mathrm{~mol}{ }^{-1}$ and PDI $=1.94$ by GPC.

Synthesis of poly[4'-(1,3-phenyl)]hexabenzocoronene-alt-2,7(9,9-dioctylfluorene) (P3) via cyclodehydrogenation

A total of 36 equivalents of iron(III) chloride in nitromethane (300 $\mathrm{mg} \mathrm{mL}^{-1}$ ) per hexaphenylbenzene unit were added dropwise to a solution of the conjugated polymer P1 (100 mg, $0.08 \mathrm{mmol})$ in dichloromethane $(100 \mathrm{~mL})$. The resulting suspension was stirred for 2 days at room temperature and a nitrogen stream was bubbled through the mixture throughout the entire reaction. The reaction was quenched with methanol (50 $\mathrm{mL})$. The black precipitate was filtered, washed with methanol followed by $\mathrm{CH}_{2} \mathrm{Cl}_{2}$ and dried under vacuum $(90 \mathrm{mg}$, yield $=90 \%)$. The extremely low solubility of $\mathbf{P 3}$ in standard solvents did not allow the characterization of the compound by NMR and GPC analyses. IR (KBr): $3078 \mathrm{~cm}^{-1}$ and $3020 \mathrm{~cm}^{-1}$ (Ar-H stretch), $2951 \mathrm{~cm}^{-1}, 2920 \mathrm{~cm}^{-1}$ and $2850 \mathrm{~cm}^{-1}(\mathrm{C}-\mathrm{H}$ stretch), $1577 \mathrm{~cm}^{-1}$ and $1458 \mathrm{~cm}^{-1}(\mathrm{C}=\mathrm{C}$ stretch in $\mathrm{Ar})$, $783 \mathrm{~cm}^{-1}, 763 \mathrm{~cm}^{-1}, 744 \mathrm{~cm}^{-1}$.

\section{Synthesis of poly[4'-(5,7-(4,4-diphenyl)biphenyl)] hexabenzocoronene-alt-2,7-(9,9-dioctylfluorene) (P4) via cyclodehydrogenation}

The title compound (P4) was prepared in a manner analogous to the procedure of $\mathbf{P 3}$ to obtain the product as black powders (yield $=65 \%) .(87 \mathrm{mg}$, yield $=88 \%)$ IR $(\mathrm{KBr}): 3080 \mathrm{~cm}^{-1}$, $3057 \mathrm{~cm}^{-1}$ and $3026 \mathrm{~cm}^{-1}$ (Ar-H stretch), $2949 \mathrm{~cm}^{-1}, 2920 \mathrm{~cm}^{-1}$ and $2848 \mathrm{~cm}^{-1}$ (C-H stretch), $1583 \mathrm{~cm}^{-1}$ and $1500 \mathrm{~cm}^{-1}(\mathrm{C}=\mathrm{C}$ stretch in Ar), $783 \mathrm{~cm}^{-1}, 763 \mathrm{~cm}^{-1}, 740 \mathrm{~cm}^{-1}$. The extremely low solubility of $\mathbf{P 4}$ in standard solvents did not allow the characterization of the compound by NMR and GPC analyses.

\section{Dispersion preparation of $\mathrm{HBC}$ derivatives}

All dispersions were prepared by bath sonication using a Branson 5510 with a frequency of $42 \mathrm{kHz}$ and a power output of $135 \mathrm{~W}$. The solvent was added to a $7 \mathrm{~mL}$ capacity vial with several milligrams of $\mathrm{HBC}$ derivatives at a concentration of $0.1 \mathrm{mg} \mathrm{mL} \mathrm{m}^{-1}$ followed by sonication for 10 minutes (these samples were not centrifuged to maintain a known concentration). The mixtures were left to settle for $48 \mathrm{~h}$ and then dispersions were characterized by UV-Vis absorption spectra, PL spectra and PLE maps.

\section{Results and discussion}

\section{Synthesis of the monomer and the conjugated polymer}

A (4-bromophenyl)pentaphenylbenzene (1) was synthesized via a Diels-Alder reaction with tetraphenylcyclopentadienone and 4-bromotolan using $\operatorname{Pd}(0)$-catalyzed Sonogashira coupling of 1-bromo-4-iodobenzene and phenylacetylene. ${ }^{16}$ The bromo group of 1 was substituted by a pinacolboronic ester through lithiation with $n$-butyllithium in THF followed by nucleophilic substitution with 2-isopropoxy-4,4,5,5-tetramethyl[1,3,2]dioxa- 
borolane to obtain the monosubstituted hexaphenylbenzene (2). One of the bromo substituents on 1,3,5-tribromobenzene or 1,3,5-tri(4-bromophenyl)benzene was subsequently substituted by a hexaphenylbenzene moiety through Suzuki coupling with 2 to give the dibromo monomer M1 or M2, respectively. The M1 and M2 monomers were polymerized with a 9,9-dioctylfluorene-2,7-diboronic acid bis(1,3-propanediol) ester by Suzuki coupling to generate the HPB-containing conjugated polymers P1 and P2. The resulting polymers are grey fibrous solids and are readily soluble in various organic solvents such as NMP, THF, toluene or $\mathrm{CH}_{2} \mathrm{Cl}_{2}$ at room temperature $\left(25^{\circ} \mathrm{C}\right)$. $\mathbf{P 1}$ and $\mathbf{P 2}$ possessed excellent organo-solubility due to the incorporation of the noncoplanar structure of HPB and fluorenes as well as aliphatic alkyl chains. ${ }^{18}$ The chemical structures of the monomers M1 and M2 as well as the polymers P1 and $\mathbf{P} 2$ were confirmed by ${ }^{1} \mathrm{H}$ - and ${ }^{13} \mathrm{C}-\mathrm{NMR}$ spectra shown in the ESI (Fig. S1-S5†), indicating that the HPB-containing polymers were successfully prepared.

\section{Cyclodehydrogenation}

The hexa-peri-hexabenzocoronene (HBC)-containing conjugated polymers P3 and P4 were synthesized by oxidative cyclodehydrogenation of $\mathbf{P 1}$ and P2, respectively (Scheme 2). Iron(III) chloride is widely used for oxidative $\mathrm{C}-\mathrm{C}$ coupling reactions as reported by Sarhan and Bolm. ${ }^{19} \mathbf{P 1}$ and P2 with hexaphenylbenzenes (HPB) moieties were therefore efficiently transformed into P3 and P4, respectively, with hexa-peri-hexabenzocoronenes (HBC) through the use of a solution of $\mathrm{FeCl}_{3}$ in nitromethane. The solution-state characterization of insoluble P3 and $\mathbf{P 4}$ is limited due to the strong $\pi-\pi$ interaction in HBCs. The MALDI-TOF MS spectrum of the model compound M3 which was prepared from M2 (Scheme S1 $\dagger$ ) is shown in Fig. S6. $\dagger$ The isotopic distribution of M3 was consistent with the simulated results, indicating an exact loss of twelve hydrogen atoms during intramolecular cyclodehydrogenation. Dilute dispersions of HBC-containing compounds were prepared by bath sonication for the optical investigations.

\section{Basic characterization}

Fourier transform infrared (FT-IR) spectroscopy analysis is a form of vibrational spectroscopy that is commonly used for
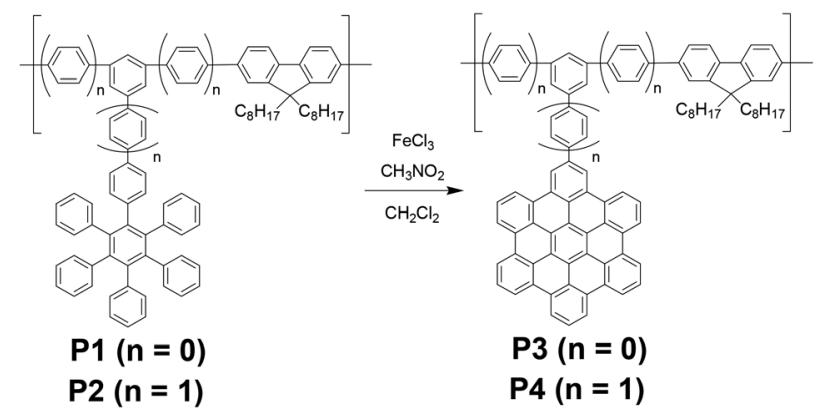

Scheme 2 Synthesis of HBC-containing conjugated polymers P3 and P4 via oxidative cyclodehydrogenation.

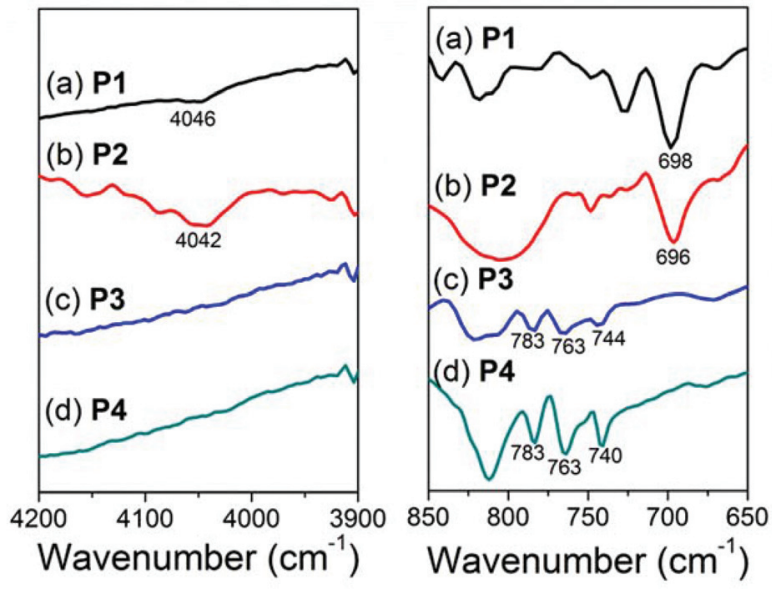

Fig. 1 FT-IR spectra of HPB-containing compounds (a) P1 and (b) P2 and HBC-containing compounds (c) P3 and (d) P4.

the solid-state characterization of HPB and HBC derivatives. $^{20,21}$ As shown in Fig. 1(a) and (b), the HPB-containing compounds P1 and P2 exhibited IR bands of $4046 \mathrm{~cm}^{-1}$ and $4042 \mathrm{~cm}^{-1}$, respectively, resulting from the free phenyl rings, which are potentially characteristic of non-condensed benzene rings. These bands were not observed in P3 and P4 due to the fused benzene ring structure of HBCs. In fingerprint bands, the five adjacent $\mathrm{C}-\mathrm{H}$ groups of monosubstituted benzene on HPB underwent out-of-plane $\mathrm{C}-\mathrm{H}$ deformation at $698 \mathrm{~cm}^{-1}$ in $\mathbf{P 1}$ as well as at $696 \mathrm{~cm}^{-1}$ in P2. In contrast, P3 and P4 possessed several peaks at 744, 763, and $783 \mathrm{~cm}^{-1}$ and at 740 , 763, $783 \mathrm{~cm}^{-1}$, respectively, as shown in Fig. 1(c) and (d), corresponding to the $\mathrm{C}-\mathrm{H}$ deformation vibration of the $\mathrm{HBC}$ moiety. Therefore, the FT-IR spectra of the cyclodehydrogenated compounds confirm the vibration features of the HBC units. The peaks at $698 \mathrm{~cm}^{-1}$ disappeared, which supports the complete cyclodehydrogenation of HPB-containing precursors into HBC-containing products.

Fig. 2 shows the thermal properties of the conjugated polymers P1-P4 as determined by differential scanning calorimetry

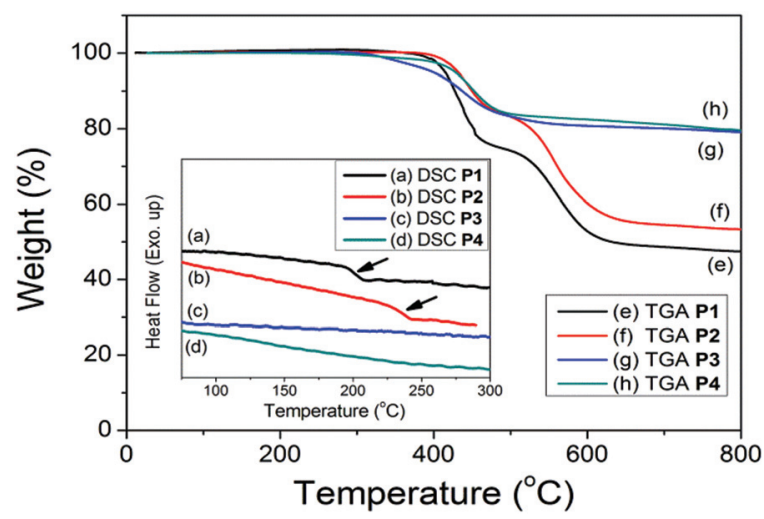

Fig. 2 DSC curves of the conjugated polymers P1-P4 and TGA curves of P1-P4 at a heating rate of $10 \mathrm{~K} \mathrm{~min}^{-1}$ under a nitrogen flow. 
Table 1 Thermal properties of conjugated polymers P1-P4

\begin{tabular}{lcll}
\hline Polymer & $T_{\mathrm{g}}{ }^{a}\left({ }^{\circ} \mathrm{C}\right)$ & $T_{\mathrm{d} 10}{ }^{b}\left({ }^{\circ} \mathrm{C}\right)$ in $\mathrm{N}_{2}$ in air & Char yield $^{c}(\%)$ \\
\hline P1 & 202 & 427 & 47 \\
P2 & 235 & 449 & 53 \\
P3 & $>300$ & 437 & 79 \\
P4 & $>300$ & 453 & 80
\end{tabular}

${ }^{a}$ Glass transition temperatures $\left(T_{\mathrm{g}} \mathrm{s}\right)$ were determined by DSC at a heating rate of $10 \mathrm{~K} \mathrm{~min}^{-1} .{ }^{b}$ Decomposition temperatures at $10 \%$ weight loss $\left(T_{\mathrm{d} 10}\right)$ were measured by TGA at a heating rate of $10 \mathrm{~K}$ $\min ^{-1} .{ }^{c}$ Residual weight percentage at $800{ }^{\circ} \mathrm{C}$ under a nitrogen flow.

(DSC) and thermogravimetric analysis (TGA). The results are summarized in Table 1. As depicted in Fig. 2, P1 and P2 possess high glass transition temperatures $\left(T_{\mathrm{g}} \mathrm{s}\right)$ of approximately 202 and $235^{\circ} \mathrm{C}$, respectively. Compared to P1, the rigidity of $\mathbf{P 2}$ backbones was enhanced by the triphenylbenzene moiety, leading to a higher $T_{\mathrm{g}}$. In addition, the phase transition of HBC-containing P3 and P4 could not be observed in the region between room temperature and $300{ }^{\circ} \mathrm{C}$, indicating that P3 and P4 exhibited excellent thermal stability caused by $\pi-\pi$ interactions among HBCs. In the TGA curve, all polymers P1-P4 showed no obvious weight loss at temperatures up to $300{ }^{\circ} \mathrm{C}$ under a nitrogen atmosphere. The temperatures required for $10 \%$ weight loss $\left(T_{\mathrm{d} 10}\right)$ of $\mathbf{P 3}$ and $\mathbf{P 4}$ were slightly higher than that for $\mathbf{P 1}$ and P2, respectively, indicating that HBCs are more thermostable than HPB. The similar degradation patterns of P1-P4 at approximately $400{ }^{\circ} \mathrm{C}$ were attributed to the decomposition of aliphatic alkyl chains attached to the fluorene moiety. However, HBC-containing P3 and P4 exhibited significantly higher char yields compared to HPBcontaining P1 and P2. This phenomenon results from further carbonization or graphitization of HBCs and leads to an increased yield of charred residue. ${ }^{22}$ Therefore, the incorporation of HBCs into conjugated polymers dramatically enhances the glass transition temperature and decomposition temperature, which are the desirable properties for polymers used in optoelectronic applications.

The powder X-ray diffractograms (XRD) of the conjugated polymers P1-P4 are shown in Fig. 3. Broad amorphous halos ( 2 theta from $10^{\circ}$ to $30^{\circ}$ ) were observed in P1-P4 attributed to the disordered aliphatic alkyl chains on the fluorene moiety. The orders of P1 and P2 were lower than P3 and P4 due to the stacking hindrance caused by the noncoplanar structure of HPB.

Cyclodehydrogenated P3 and P4 exhibited a $d$-spacing of 1.26 and $1.37 \mathrm{~nm}$, respectively, associated with the interlayer distance being dependent on the HBC size. In addition, the $\pi-\pi$ stacking distance (3.4-3.7 $\AA$ ) in planar polycyclic aromatic hydrocarbons was also observed in P3 and P4. Based on the XRD spectra, the $d$-spacings of the HBC moieties on P3 and P4 were slightly smaller than the $15 \AA$ spacing of HBCs ascribed to a possible tilted arrangement of the HBC moieties. Thus, the XRD results of $\mathbf{P} 3$ and $\mathbf{P 4}$ show a highly efficient transformation from HPB to HBCs through complete cyclodehydrogenation.
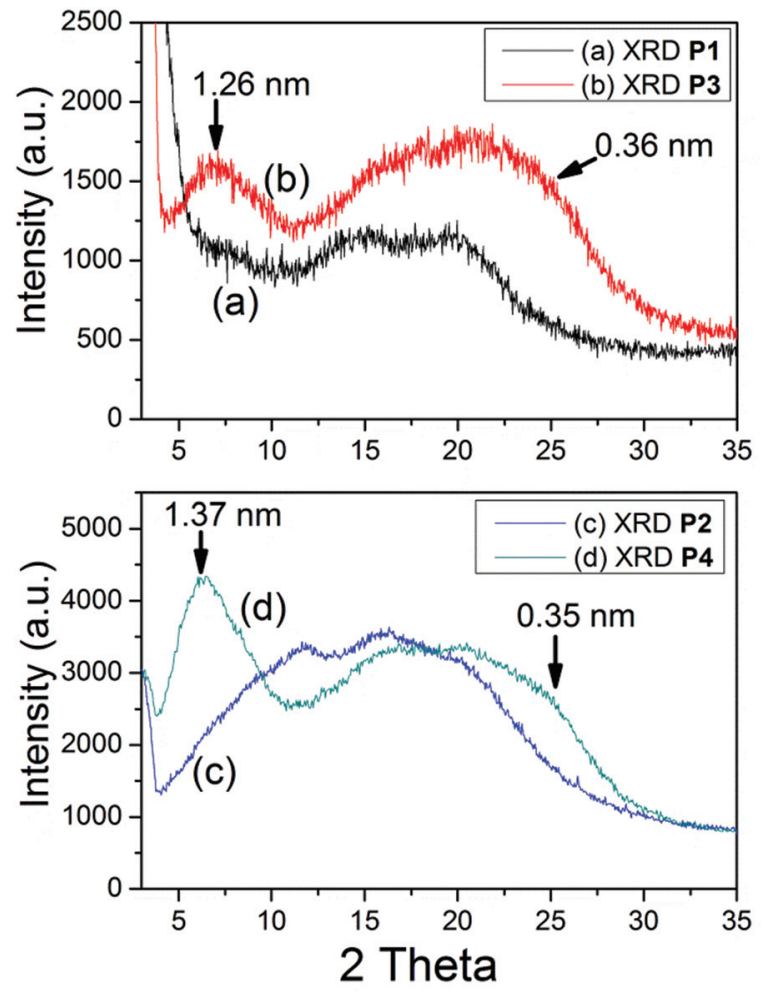

Fig. 3 Powder X-ray diffraction of conjugated polymers (a) P1, (b) P3, (c) P2 and (b) P4.

\section{Optical properties of HPB-containing P1 and P2}

Fig. 4 shows the UV-Vis absorption and PL spectra of HPB-containing conjugated polymers $\mathbf{P 1}$ and $\mathbf{P 2}$ in THF solution $\left(10^{-5} \mathrm{M}\right)$. As shown in Fig. 4(a) and (b), both P1 and P2 exhibited shoulder absorption bands approximately at $310 \mathrm{~nm}$ caused by the $\pi-\pi^{*}$ transition of polyphenyl groups such as quarterphenyl or pentaphenyl. ${ }^{23}$ In addition, the conjugated polymers P1 and P2 showed absorbance at 332 and $341 \mathrm{~nm}$, respectively, attributed to the $\pi-\pi^{*}$ transition of the polymer backbones. ${ }^{24}$

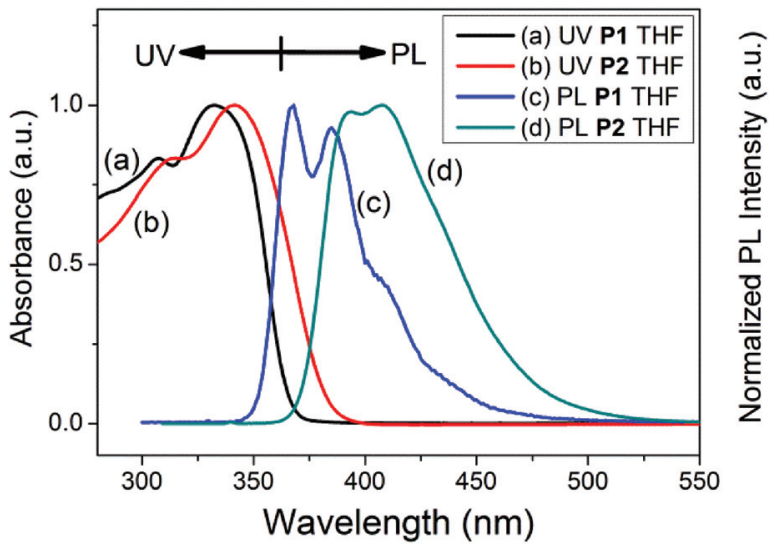

Fig. 4 UV-Vis absorption of (a) P1 and (b) P2 as well as PL spectra of (c) $\mathrm{P} 1$ and (d) P2 in THF solution $\left(10^{-5} \mathrm{M}\right)$. 
Compared to $\mathbf{P 1}$, the red-shifted phenomenon of $\mathbf{P} 2$ was observed at approximately $10 \mathrm{~nm}$ as shown in Fig. 4(b), ascribed to the enhancement of the conjugation length. The photoluminescence spectra of $\mathbf{P 1}$ and $\mathbf{P 2}$ in solution possessed maximum emission peaks at 368 and $408 \mathrm{~nm}$, respectively. The bathochromic shift of the $\mathbf{P 2}$ emission band was ascribed to the longer conjugation length of the backbone. P1 and P2 in THF possessed high fluorescence quantum yields of about 0.88 and 0.92 , respectively, which were higher than the yield of 0.78 of poly(9,9-di- $n$-octylfluorene $)^{25}$ and the yield of 0.44 of triphenylbenzene and fluorene derivatives, ${ }^{24}$ indicating that the propeller-like shape and steric bulkiness of HPB units impede intramolecular rotation and reduce the nonradiative decay of the excited state. ${ }^{26}$

\section{Optical properties of HBC-containing P3 and P4}

P3 and P4 are insoluble in common organic solvents due to the strong $\pi-\pi$ interactions among the HBC units. However, using an ultrasonic agitation technique, it was possible to obtain a dispersion of HBC derivatives in organic solvents for UV-Vis absorption and photoluminescence spectroscopy analyses. Fig. 5 shows the UV-Vis absorption and PL spectra of P3 and $\mathbf{P 4}$ dispersed in CHP. The absorption bands appearing approximately at $360 \mathrm{~nm}$ were termed $\beta$-bands (full symmetry allowed), and the shoulder at $427 \mathrm{~nm}$ was termed p-bands (partial symmetry forbidden), on the basis of Clar's nomenclature. $^{27}$ In Fig. 5(a) and (b), the $\beta$-bands of P3 and P4 were located at $369 \mathrm{~nm}$ and $361 \mathrm{~nm}$, respectively. Compared to P4, the $\mathbf{P} 3$ dispersion with a higher absorption wavelength is due to the ease of HBC $\pi-\pi$ stacking, leading to a longer conjugation length. As mentioned by Kastler et al., the intensities of the aggregate emissions of the alkylated HBCs increase with their increasing concentration in organic media. Therefore, the PL spectra could be regarded as secondary measurement of the aggregation phenomena of the HBCs. As shown in Fig. 5(c), P3 revealed broad emission bands at 466, 534 and $636 \mathrm{~nm}$. The emission bands beyond $600 \mathrm{~nm}$ were caused by

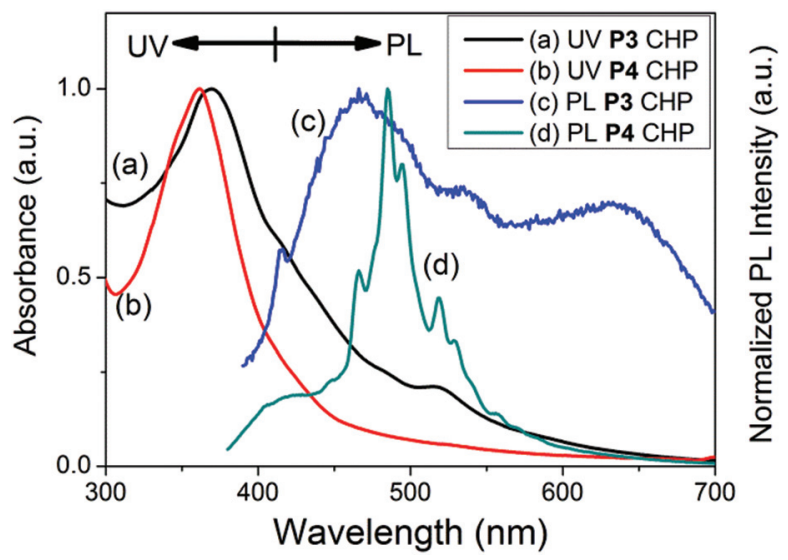

Fig. 5 (a) UV-Vis absorption spectra of (a) P3 and (b) P4 as well as PL spectra of (c) P3 excited at $369 \mathrm{~nm}$ and (d) P4 excited at $361 \mathrm{~nm}$ $\left(0.1 \mathrm{mg} \mathrm{mL}^{-1}\right)$ in CHP. aggregation of the HBC moiety, indicating that $\mathbf{P} 3$ could not be well dispersed in CHP. ${ }^{13}$ In contrast, $\mathbf{P 4}$ shows resolved emission peaks at $466,485,495,519$ and $529 \mathrm{~nm}$ attributed to the photoluminescence of completely exfoliated and disaggregated HBCs. In addition, the emission bands beyond $600 \mathrm{~nm}$ were not observed, indicating that the $\mathbf{P 4}$ polymer existed individually in CHP.

Fig. 6 displays the UV-Vis absorption spectra of conjugated polymer P3 and P4 dispersions in THF. As shown in Fig. 6(a) and (b), P3 and P4 showed transitions at $371 \mathrm{~nm}$ and $365 \mathrm{~nm}$, respectively. The p-band absorbance $(\sim 427 \mathrm{~nm})$ increased with increasing concentrations of $\mathbf{P 4}$ in THF (Fig. S7 $\dagger$ ), resulting from the aggregation of HBC units at high dispersion concentrations. Therefore, the dispersion of P3 and P4 in different solvents could be determined by the intensity ratio $\left(A_{\text {max }} / A_{427}\right)$ Ind of $\beta$-bands at $\sim 360 \mathrm{~nm}$ (associated with the presence of exfoliated molecules) to p-bands at $\sim 427 \mathrm{~nm}$ (associated with the presence of aggregated HBCs). Here "Ind" indicates individual. The ratio $\left(A_{\max } / A_{427}\right)_{\text {Ind }}$ reflects the relative content of the exfoliated HBC-containing $\mathbf{P 3}$ and P4. When the individual population is high, the ratio will increase due to lower levels of aggregation. As tabulated in Table 2, $\mathbf{P 3}$ possessed $\left(A_{\max } / A_{427}\right)$ Ind ratios of 1.96 and $1.51 \mathrm{in} \mathrm{CHP} \mathrm{and} \mathrm{THF,}$ respectively. On the other hand, $\mathbf{P 4}$ exhibited $\left(A_{\max } / A_{427}\right)$ Ind ratios of 4.47 and 1.76 in $\mathrm{CHP}$ and $\mathrm{THF}$, respectively. Compared to THF as a dispersant, CHP is an excellent solvent for the dispersion of HBC-containing P3 and P4 due to its large $\left(A_{\max } / A_{427}\right)$ Ind ratio. This feature could be a result of the similar Hildebrand solubility parameters of both $\mathrm{HBC}$ and CHP, approximately $21 \mathrm{MPa}^{1 / 2}$, which results in good dissolution and a low enthalpy of mixing between the solute and the solvent. ${ }^{14}$ It is noteworthy that $\mathbf{P 4}$ showed a higher dispersibility than P3, resulting from the triphenylbenzene moiety possessing more free volume for solvent penetration and steric hindrance for HBC stacking. As shown in Fig. 6(c), P3 shows an intensive emission band at $659 \mathrm{~nm}$ due to the aggregation of HBC groups. Compared to P3 in Fig. 6(c), the P4 dispersion exhibited resolved peaks in the region between 450 and

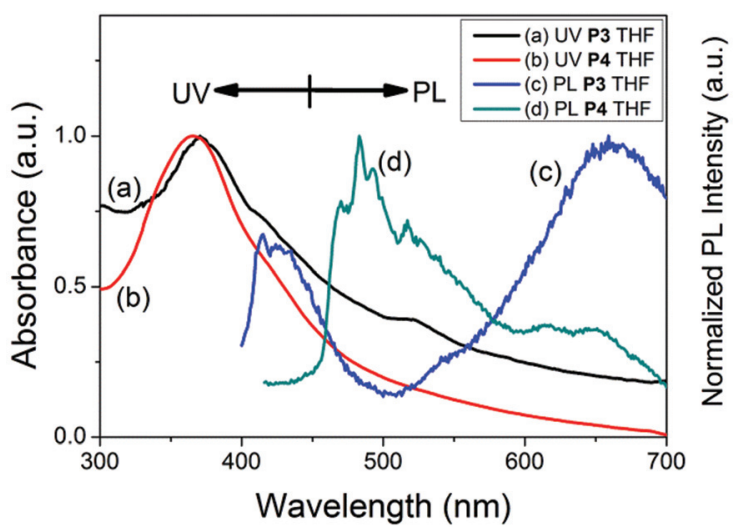

Fig. 6 (a) UV-Vis absorption spectra of (a) P3 and (b) P4 as well as PL spectra of (c) P3 excited at $371 \mathrm{~nm}$ and (d) P4 excited at $365 \mathrm{~nm}$ (0.1 $\mathrm{mg} \mathrm{mL}^{-1}$ ) in THF. 
Table 2 Optical properties of P3 and P4 dispersed in different solvents

\begin{tabular}{lllll}
\hline & \multicolumn{2}{l}{ Dispersion $\lambda(\mathrm{nm})$} & & \\
\cline { 2 - 5 } Polymer & Solvent & Abs. max. & PL $^{b}$ & $\left(A_{\text {max }} / A_{427}\right)_{\text {Ind }}{ }^{c}$ \\
\hline P3 & CHP & $369(0.216)^{a}$ & $466,534,636$ & 1.96 \\
P4 & CHP & $361(0.254)^{a}$ & $466,485,495,519,529$ & 4.47 \\
P3 & THF & $371(0.067)^{a}$ & 416,659 & 1.51 \\
P4 & THF & $365(0.198)^{a}$ & $470,483,493,517,526,616,651$ & 1.76
\end{tabular}

${ }^{a}$ The absorbance value of dispersions $\left(0.1 \mathrm{mg} \mathrm{mL}^{-1}\right)$ from the UV-Vis spectra. ${ }^{b}$ The excitation wavelength was at Abs. max. of the dispersions. ${ }^{c}$ The ratio of absorbance at Abs. max. to absorbance at $427 \mathrm{~nm}$ for the exfoliation of $\mathbf{P} 3$ and $\mathbf{P 4}$.

$550 \mathrm{~nm}$ and weak bands beyond $600 \mathrm{~nm}$ in Fig. 6(d), indicating that $\mathbf{P 4}$ was still well exfoliated in THF.

Fig. 7 shows the photoluminescence-excitation (PLE) maps of HBC-containing conjugated polymer P3 and P4 dispersions. While P3 dispersed in CHP and THF as shown in Fig. 7(a) and (b), the unresolved emission bands were observed at $450 \mathrm{~nm}$ and $650 \mathrm{~nm}$, respectively. The broad emission bands appeared $\left(\lambda_{\text {em }}>600 \mathrm{~nm}\right.$ and $\lambda_{\text {ex }} \sim 350-380 \mathrm{~nm}$ ) attributed to the aggregation of HBC moieties, indicating that P3 could not be exfoliated in solvents. As shown in Fig. 7(c), P4 dispersed in CHP exhibited an emission-excitation region at $495 \mathrm{~nm}$ excited by $361 \mathrm{~nm}$ (i.e., $\beta$-transition) and emission bands above $600 \mathrm{~nm}$ were not observed, which could be considered a result of the individual emissions of the HBC units, indicating that $\mathbf{P 4}$ was well dispersed in CHP. When $\mathbf{P 4}$ was dispersed in THF, as shown in Fig. 7(d), some weak and broad emission bands appeared $\left(\lambda_{\mathrm{em}}>600 \mathrm{~nm}\right.$ and $\left.\lambda_{\mathrm{ex}} \sim 350-370 \mathrm{~nm}\right)$, which can be attributed to excimer-like emissions from few aggregated HBC units. In comparison with $\mathbf{P} 3$ dispersion, $\mathbf{P 4}$ dispersed well in organic solvents without significant aggregation. Due to the noncoplanar and bulky triphenylbenzene of $\mathbf{P 4}$ backbones, $\pi-\pi$ interactions among the HBC moieties were slightly hindered. In addition, no precipitation of P3 and P4 dispersions was
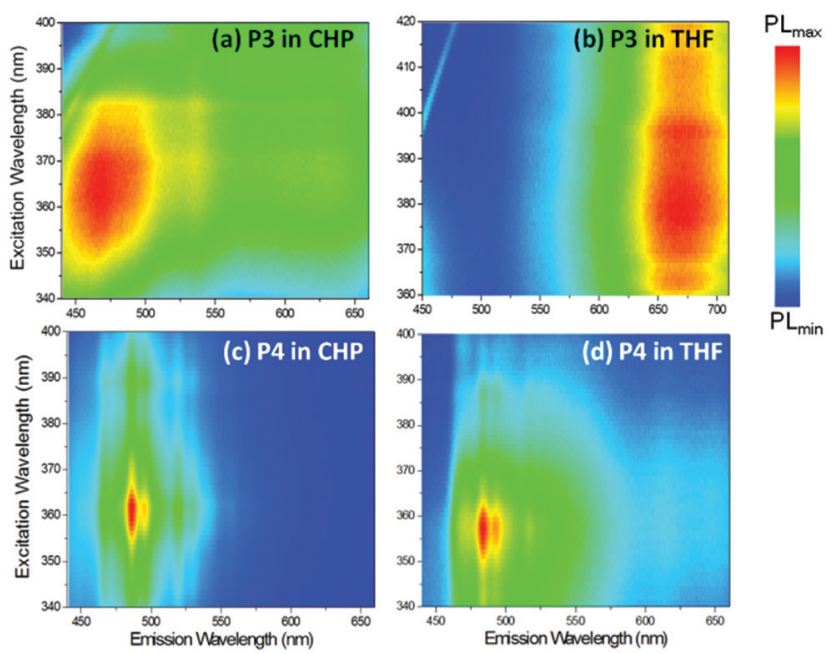

Fig. 7 Excitation-emission maps of dispersion $\left(0.1 \mathrm{mg} \mathrm{mL}^{-1}\right)$ with HBC-containing P3 in (a) CHP, (b) THF as well as P4 in (c) CHP and (d) THF. observed over several days indicating the long time stability of the dispersions.

\section{Conclusions}

In summary, novel HPB-containing polymers (P1 and P2) and nanographene-containing polymers (P3 and P4) were successfully synthesized via Suzuki coupling and cyclodehydrogenation, respectively. The exfoliation of HBC-containing conjugated polymers P3 and P4 was carried out in organic solvents prepared by sonication to obtain stable and high quality dispersions. Compared to $\mathbf{P 3}$ dispersion, the incorporation of triphenylbenzene into $\mathbf{P 4}$ backbones showed better dispersibility in organic solvents. Therefore, the dispersion of $\mathbf{P 4}$ can be considered as a prototype for the exfoliation of graphene-containing polymers and can be used for further optoelectronic applications.

\section{Acknowledgements}

The authors would like to thank the Ministry of Science and Technology (MOST) of Taiwan for the financial support for this work.

\section{Notes and references}

1 K. S. Novoselov, A. K. Geim, S. V. Morozov, D. Jiang, Y. Zhang, S. V. Dubonos, I. V. Grigorieva and A. A. Firsov, Science, 2004, 306, 666-669.

2 A. K. Geim and K. S. Novoselov, Nat. Mater., 2007, 6, 183-191.

3 M. J. Allen, V. C. Tung and R. B. Kaner, Chem. Rev., 2010, 110, 132-145.

4 R. Rieger and K. Müllen, J. Phys. Org. Chem., 2010, 23, 315-325.

5 A. Narita, X.-Y. Wang, X. Feng and K. Mullen, Chem. Soc. Rev., 2015, 44, 6616-6643.

6 M. Müller, C. Kübel and K. Müllen, Chem. - Eur. J., 1998, 4, 2099-2109.

7 J. Wu, W. Pisula and K. Müllen, Chem. Rev., 2007, 107, 718747.

8 C.-y. Liu, A. Fechtenkötter, M. D. Watson, K. Müllen and A. J. Bard, Chem. Mater., 2003, 15, 124-130. 
9 A. M. van de Craats, N. Stutzmann, O. Bunk, M. M. Nielsen, M. Watson, K. Müllen, H. D. Chanzy, H. Sirringhaus and R. H. Friend, Adv. Mater., 2003, 15, 495-499.

$10 \mathrm{~J} . \mathrm{Wu}, \mathrm{A} . \mathrm{C}$. Grimsdale and K. Mullen, J. Mater. Chem., 2005, 15, 41-52.

11 J. M. Warman, J. Piris, W. Pisula, M. Kastler, D. Wasserfallen and K. Müllen, J. Am. Chem. Soc., 2005, 127, 14257-14262.

12 W. W. H. Wong, T. B. Singh, D. Vak, W. Pisula, C. Yan, X. Feng, E. L. Williams, K. L. Chan, Q. Mao, D. J. Jones, C.-Q. Ma, K. Müllen, P. Bäuerle and A. B. Holmes, Adv. Funct. Mater., 2010, 20, 927-938.

13 J. M. Englert, F. Hauke, X. Feng, K. Mullen and A. Hirsch, Chem. Commun., 2010, 46, 9194-9196.

14 J. M. Hughes, Y. Hernandez, D. Aherne, L. Doessel, K. Müllen, B. Moreton, T. W. White, C. Partridge, G. Costantini, A. Shmeliov, M. Shannon, V. Nicolosi and J. N. Coleman, J. Am. Chem. Soc., 2012, 134, 12168-12179.

15 Y. Hernandez, V. Nicolosi, M. Lotya, F. M. Blighe, Z. Sun, S. De, I. T. McGovern, B. Holland, M. Byrne, Y. K. Gun'Ko, J. J. Boland, P. Niraj, G. Duesberg, S. Krishnamurthy, R. Goodhue, J. Hutchison, V. Scardaci, A. C. Ferrari and J. N. Coleman, Nat. Nano, 2008, 3, 563-568.

16 C. Kübel, S.-L. Chen and K. Müllen, Macromolecules, 1998, 31, 6014-6021.
17 I. A. Khotina, O. E. Shmakova, D. Y. Baranova, N. S. Burenkova, A. A. Gurskaja, P. M. Valetsky and L. M. Bronstein, Macromolecules, 2003, 36, 8353-8360.

18 D.-J. Liaw, F.-C. Chang, M.-k. Leung, M.-Y. Chou and K. Muellen, Macromolecules, 2005, 38, 4024-4029.

19 A. A. O. Sarhan and C. Bolm, Chem. Soc. Rev., 2009, 38, 2730-2744.

20 A. Centrone, L. Brambilla, T. Renouard, L. Gherghel, C. Mathis, K. Müllen and G. Zerbi, Carbon, 2005, 43, 15931609.

21 M. G. Schwab, A. Narita, Y. Hernandez, T. Balandina, K. S. Mali, S. De Feyter, X. Feng and K. Müllen, J. Am. Chem. Soc., 2012, 134, 18169-18172.

22 F. Cataldo, O. Ursini, G. Angelini and S. Iglesias-Groth, Fullerenes, Nanotubes, Carbon Nanostruct., 2011, 19, 713725.

23 X. Lu, C. He, P. Liu and A. C. Griffin, J. Polym. Sci., Part A: Polym. Chem., 2005, 43, 3394-3402.

24 X. Wu, H. Li, Y. Xu, H. Tong and L. Wang, Polym. Chem., 2015, 6, 2305-2311.

25 C. Xia and R. C. Advincula, Macromolecules, 2001, 34, 58545859.

26 R. Hu, J. W. Y. Lam, Y. Liu, X. Zhang and B. Z. Tang, Chem. - Eur. J., 2013, 19, 5617-5624.

27 G. Rouillé, M. Steglich, F. Huisken, T. Henning and K. Müllen, J. Chem. Phys., 2009, 131, 204311. 